10 World Health Organisation Study Group. Diabetes mellitus. WHO Tech Rep Ser 1985 ; No 727 .

11 Harris $\mathrm{H}$. The familial distribution of diabetes mellitus: a study of the relatives of 1241 diabetic propositi. Annals of Eugenics 1950;15:95-119.

12 Dahlqvist G, Blom L, Tuvemo T, Nyström L, Sandström A, Wall S. The Swedish childhood diabetes study. Results from a nine year case register and a one year case-referent study indicating that type 1 (insulin-dependent) a one year case-referent study indicating that type 1 (insulin-dependent)
diabetes mellitus is associated with both type 2 (non-insulin-dependent) diabetes mellitus is associated with both type 2 (non-insulin-depende
diabetes mellitus and autoimmune disorders. Diabetologia 1989;32:2-6.

13 Tuomilehto J, Lounamaa R, Tuomilehto-Wolf E, Reunanen A, Virtala E, Kaprio EA, et al. Epidemiology of childhood diabetes in Finland. Background of a nationwide study of type 1 (insulin-dependent) diabetes mellitus. Diabetologia 1992;35:70-6.

14 Diabetes Epidemiology Research International Group. Geographic patterns of childhood insulin-dependent diabetes mellitus. Diabetes 1988;37:1113-9.

15 Rewers M, LaPorte RE, King HOM, Tuomilehto J. Insulin-dependent diabetes mellitus in childhood: international patterns and trends. World Health Stat $Q 1988 ; 41: 179-89$

16 Tuomilehto-Wolf E, Tuomilehto J, Cepatis Z, Lounamaa R, DIME Study Group. New susceptibility haplotype for type 1 diabetes. Lancet 1989;ii:299302 .

17 Tuomilehto J, Nissinen A, Kivelä S-L, Pekkanen J, Kaarsalo E, Wolf E, et al. Prevalence of diabetes mellitus in elderly men aged 60 to 84 years in eastern and western Finland. Diabetologia 1986;29:611-5.

8 Tuomilehto J, Korhonen H, Kartovaara L, Salomaa V, Stengård JH, Pitkänen $\mathrm{M}$, et al. Prevalence of diabetes mellitus and impaired glucose tolerance in the middle-aged population of three areas in Finland. Int $\mathcal{f}$ Epidemiol 1991;20:1010-7.

19 Tienari PJ, Tuomilehto-Wolf E, Tuomilehto J, Peltonen L, Childhood Diabetes in Finland Study Group. HLA haplotypes in type 1 (insulindependent) diabetes mellitus: molecular analysis of the HLA-DQ locus. Diabetologia 1992;35:254-60.

20 Keys A, ed. Coronary heart disease in seven countries. Circulation 1970;41 (suppl 1):1-211.

21 Nissinen A, Kivelä S-L, Pekkanen J, Tuomilehto J, Kostiainen E, Piippo H, et al Levels of some biological risk indicators among elderly men in Finland. Age Ageing 1986;15:203-11.

22 Pekkanen J, Nissinen A, Puska P, Punsar S, Karvonen MJ. Risk factors and 25 year risk of coronary heart disease in a male population with a high incidence of the disease: the Finnish cohorts of the seven countries study. $B M \mathcal{F}$ 1989;299:81-5.
23 Tuomilehto-Wolf E, Tuomilehto J, Hitman G, Childhood Diabetes in Finland Study Group. DQA1 and DQB1 heterodimers in insulin-dependent diabetes mellitus: a genetic-epidemiological study in Finland. Ann Med 1992;24:533-8.

24 Baur MP, Neugebauer M, Albert ED. Reference tables of three-locus haplotype frequencies and delta values in Caucasians, orientals and
negroids. In: Albert ED, Baur MP, Mayr WR, eds. Histocompatibility negroids. In: Albert ED, Baur

25 Briggs BR, Botha MC, Jackson WPU, DuToit ED. The histocompatibility (HLA) antigen distribution in South African blacks (Xhosa). Diabetes 1980;29:68-70.

26 Williams C, Knowler WC, Butler WJ, Pettitt DJ, Lisse JR, Bennett PH, et al. HLA-A2 and type 2 (insulin-dependent) diabetes mellitus in Pima Indians: an association of allele frequency with age. Diabetologia 1981;21:460-3.

27 Serjeantson SW, Ryan DP, Ram P, Zimmet P. HLA and non-insulindependent diabetes mellitus in Fiji Indians. Med f Aust 1981;i:462-3.

28 Asmal AC, Dayal B, Jialal I, Leary WP, Omar MAK, Pillay NL, et al. Noninsulin-dependent diabetes mellitus with early onset in blacks and Indians. $S$ Afr Med f 1981;60:93-6.

29 Omar MAK, Hammond MG, Motala AA, Seedat MA. HLA class I and II antigens in South African Indians with non-insulin dependent diabetes mellitus. Diabetes 1988;37:796-9.

30 Wolf E, Drummond V, Savage M, Dean B, Bottazzo GF, Davidson JC, et al. HLA and islet cell antibodies in diabetics from the West Indies, Qatar and Brazil. Diabetologia 1981;21:A80.

31 Groop L, Koskimies S, Pelkonen R, Tolppanen E-M. Increased frequency of HLA-Cw4 in type 2 diabetes. Acta Endocrinol 1983;104:475-8.

32 Zhao $\mathrm{T}$, Chi $\mathrm{Z}$, Wang $\mathrm{H}$, Shen $\mathrm{M}$, Zhou $\mathrm{Z}$, Bu K, et al. HLA and diabetes mellitus in China. Chin Med f 1982;95:609-12.

33 Serjeantson SW, Owerbach D, Zimmet P, Nerup J, Thoma K. Genetics of diabetes in Nauru: effects of foreign admixture, HLA antigens and the insulin-gene-linked polymorphism. Diabetologia 1983;25:13-5.

34 Bhatia K, Patel M, Gorogo M. Type 2 (non-insulin dependent) diabetes mellitus and HLA antigens in Papua, New Guinea. Diabetologia 1984;27: 370-3.

35 Spees EK, Kostyu DD, Elston RC, Amos DB. HL-A profiles of the Pima Indians of Arizona. In: Dausset J. Colombani J, eds. Histocompatibility testing. Copenhagen: Munksgaard, 1973:345-9.

(Accepted 11 May 1993)

\title{
Routine ultrasonography in utero and subsequent handedness and neurological development
}

\author{
Kjell Å Salvesen, Lars J Vatten, Sturla H Eik-Nes, Kenneth Hugdahl, Leiv S Bakketeig
}

\section{Abstract}

Objective-To examine any associations between routine ultrasonography in utero and subsequent brain development as indicated by non-right handedness at primary school age and neurological development during childhood.

Design-Follow up of 8 and 9 year old children of women who took part in two randomised, controlled trials of routine ultrasonography during pregnancy.

Setting-Clinics of 60 general practitioners in Norway during 1979-81. Maternal and child health centres.

Subjects-2161 (89\%) of 2428 eligible singletons were followed up, partly through a questionnaire to their parents and partly through information from health centres.

Main outcome measures-The dominant hand of the child was assessed by 10 questions. Deficits in attention, motor control, and perception were evaluated by five questions. Impaired neurological development during the first year of life was assessed by an abbreviated version of the Denver developmental screening test.

Results-The odds of non-right handedness were higher among children who had been screened in utero than among control children (odds ratio 1.32; $95 \%$ confidence interval 1.02 to $1 \cdot 71)$. No clear differences were found between the groups with regard to deficits in attention, motor control, and perception or neurological development during the first year of life.

Conclusion-Our data suggest a possible association between routine ultrasonography in utero and subsequent non-right handedness, whereas no association with impaired neurological development was found. As the question on non-right handedness was one of six initial hypotheses, the observed results may be due to chance. None the less, the results suggest that the hypothesis may have some merit and should be tested in future studies.

\section{Introduction}

The common indications for diagnostic ultrasound scanning in pregnancy and the routine screening offered in some countries result in most pregnant women in developed countries being exposed to the procedure. No adverse effects of diagnostic ultrasound screening in pregnancy have been reported. Possible long term effects among children exposed to ultrasound in utero, however, have been examined in only a few studies. The general consensus is that further research on this topic is warranted.'

Abnormal development is typically related to disturbances during critical stages of gestation. Routine ultrasonography is usually done between the 16th and the 22nd week of pregnancy, which is an important phase of brain development. ${ }^{2}$ At this point neurones migrate towards their destination in the fetal brain. Experimental studies in vitro have shown changes in the cell membrane ${ }^{3}$ and cell surface motility and architecture ${ }^{4}$ after exposure to ultrasound. Ultrasound might influence neuronal migration, and it has been suggested that altered cerebral dominance, dyslexia, or impaired neurological development may be the result of a disturbed migration of neurones. ${ }^{5}$ The dominant hand may serve as an indicator of cerebral dominance. The normal high prevalence of right handedness means that random damage to the hemispheres will increase left handedness. ${ }^{6}$ 
Long term follow up of infants in randomised clinical trials has been recommended to answer questions about the effect of ultrasound on human development. ${ }^{7}$ In a previous report we were unable to find any association between routine ultrasonography in utero and poor performance at school or dyslexia among 8 and 9 year old children. ${ }^{8}$ Nor did we find any differences in vision or hearing at ages 4 and $7 .^{9}$ In the present report on the same children we aimed to find out whether routine ultrasonography was associated with changes in handedness patterns or with impaired neurological development.

\section{Subjects and methods}

Two randomised controlled trials of ultrasonographic screening in pregnancy were carried out in the Norwegian cities of Trondheim and Ålesund in 1979$81 .{ }^{1011}$ The study design and methods of randomisation (sealed envelope method) were identical. The pregnant women in Ålesund were representative of the general population, ${ }^{11}$ whereas the study population in Trondheim included more low risk pregnancies. ${ }^{10}$ The study women were offered ultrasonographic examinations in the 19th and 32nd weeks of pregnancy. The same ultrasonic devices (ADR 2130, Tempe, Arizona) were used in Trondheim and Ålesund. Those scanners produced lower intensities than do most scanners in obstetric use today. The median exposure time for the first routine scan in Ålesund was three minutes.

Altogether 2637 women were randomised into a screening group of 1335 women and 1302 controls. Among the screened women there were 15 pairs of twins, 55 abortions, and eight perinatal deaths among singletons. The whereabouts of 13 women could not be traced eight years after the original studies, leaving 1244 eligible, live born singletons to be followed up in 1988. In the control group, there were 10 pairs of twins, one set of triplets, 66 abortions, 11 perinatal deaths among singletons, three late neonatal deaths, and 27 women who could not be found, leaving 1184 eligible singletons for the present study.

Mothers of all the 2428 eligible children were sent a questionnaire together with an information letter and a postage paid return envelope. The questionnaire consisted of 66 closed questions on sociodemographic data; the child's health, hearing, and vision; and specific questions about dominant hand and neurological development. We specifically included questions about family history of dyslexia, left handedness, and allergy and about social variables such as parental years of education, parental occupation, and family income. Immune diseases were of particular interest because of a reported triadic association among immune disease, dyslexia, and left handedness, ${ }^{5}$ and these were covered in four questions. Return of the questionnaire was taken as informed consent for the child to take part in the follow up study. Two reminders were sent to non-responders.

Norwegian children are regularly examined by physicians and specially trained public health nurses at maternal and child health centres. Visits take place when a child is 6 weeks old and at 3, 6, and 12 months and at 2, 4, and 7 years of age. The prospectively recorded data from these examinations were collected for each child in the study. The staff at the maternal and child health centres were not aware of whether the child had been exposed to ultrasound or the objectives of the study.

Among six stated hypotheses in the study protocol, two dealt with vision and hearing and four with possible effects of routine ultrasonography on the developing fetal brain. These included increased incidence of dyslexia; deficits in attention, motor control, and perception; impaired neurological development during the first year of life; and changes in handedness. Analyses of the association between ultrasound scanning and dyslexia have been reported elsewhere. ${ }^{8}$

\section{HANDEDNESS}

The dominant hand of the child was assessed with 21 questions taken from a modified version of a questionnaire developed by Rackzowski and coworkers. ${ }^{22}$ The parents answered specific questions about which hand the child preferred to use while performing various tasks in daily life activities. They were instructed not to respond if they had never observed the child do the task in question. Response options were the left hand, equally often with either hand, or the right hand.

Before the study we had decided to include questions on a variety of activities and to exclude questions that were not responded to with reasonable frequency. We had not, however, decided which questions to include in the analysis before the study.

Complete data on all 21 questions was available for only 1210 children $(50 \%)$. In a trade off between increasing statistical power and losing information by dropping questions, we decided to use information from 10 of the 21 questions. These included which hand the child preferred when drawing, writing, dealing cards, using a bottle opener, throwing a ball, using an eraser and a pair of scissors, eating with a spoon and a fork, and cutting with a knife. Complete data were available from 1663 children (69\%). The 10 items represented various aspects of activities of the daily life of an 8 or 9 year old child (doing school work, playing games, having a meal, and using a tool) and received a fairly high response rate. A child was classified as being right handed or left handed if at least nine of the 10 questions were answered as such. Children were classified as non-right handed if they were not right handed, thereby including all children who were left handed.

The data were also analysed with a quantitative approach by using a handedness score based on the 10 selected questions. If none of the 10 questions were answered as right handed, the handedness score was 0 . If all 10 questions were answered as right handed, the handedness score was 10. The distribution of this laterality score was, of course, highly skewed towards right handedness. Thus, the handedness score was compared between screened and control children with non-parametric statistics.

\section{NEUROLOGICAL DEVELOPMENT DURING FIRST YEAR} OF LIFE

Neurological development in infancy is closely monitored at the maternal and child health centres. The original Denver developmental screening test included 105 items which cover four developmental functions in infants and preschool children (gross motor, language, fine motor-adaptive, and personalsocial functions) ${ }^{13}$ In Norway a modified version with 10 items has been used for the past 20 years, including six items for gross motor functions: prone, lifts the head up 90 degrees (should be achieved by the age of 5 months); rolls over (6 months); sits without support (9 months); pulls self to stand (11 months); walks holding on to furniture (12 months); and walks well (14 months). Four items for personal-social, language, and fine motor-adaptive functions comprise smiles responsively (should be achieved by 4 months); imitates speech sounds ( 7 months); thumb-finger grasp (10 months); and three words other than "mama" or "dada" (14 months).

A child was included in the analyses if information on at least one of the 10 items from the short version of the Denver test was available. Children were classified as having impaired neurological development if they had not achieved one of the 10 functions at the 
expected age. In addition, mothers reported in the questionnaire at what age their child started to walk.

ATTENTION, MOTOR CONTROL, AND PERCEPTION

Deficits in attention, motor control, and perception have been replaced by the initial description minimal brain dysfunction. This may be a sign of impaired neurological development, which is first detectable in preschool children. It has been shown that this condition has a prevalence of $7 \%$ among preschool children in Sweden. ${ }^{14}$

We used a questionnaire that was specifically developed to identify children with deficits in attention, motor control, and perception with a reported sensitivity of $74 \%$ and a specificity of $92 \% .{ }^{15}$ One of the original six questions, however, apparently did not identify children with deficits in attention, motor control, and perception in our study. Thus almost one third of parents agreed that their child moved about by "shuffling" before starting to walk implying that as many as one third of the children had signs of deficits in attention, motor control, and perception. When we restricted the analysis to the remaining five questions, $15 \%$ of the children in the study were classified as having deficits in attention, motor control, and perception.

POWER CALCULATIONS AND STATISTICAL ANALYSIS

With a given sample size of 1000 children in each group and a two sided $\alpha$ of 0.05 and a $\beta$ of $0 \cdot 10$, power calculations before the study showed that we would be able to detect a $25 \%$ increase in the prevalence of nonright handedness (from a base prevalence of $15-21 \%$ ). Analogously, a $50 \%$ increase in left handedness from a prevalence of $9-13 \%$ and a $75 \%$ increase in the prevalence of deficits in attention, motor control, and perception from 5-9\% would be detected. Power calculation of the hypothesis of impaired neurological development during the first year of life had not been done before the study.

Analyses were done with the statistical package for the social sciences. ${ }^{16}$ We compared proportions of missing data between groups with Mantel-Haenszel $\chi^{2}$ statistics. The associations between routine ultrasonography and subsequent handedness; neurological impairment; and deficits in attention, motor control, and perception were assessed by using the odds ratio as a measure of relative risk. The precision of the odds ratio is presented as $95 \%$ confidence intervals, calculated from Mantel-Haenszel $\chi^{2}$ statistics. ${ }^{17}$ Differences in the mean age at walking between the two groups of children was tested with Student's $t$ test. The handedness score was compared between groups with the Mann-Whitney test.

Data were collected from randomised controlled trials in two centres with identical study design and method of randomisation. The analyses were first done stratified by centre but as the results were homogeneous pooled estimates are presented.

\section{Results}

Of 1244 children in the screened group, 1115 were studied; five had died (two of congenital heart disease and three of sudden unexpected death in infancy), and the parents of 124 did not respond to the questionnaire. In the control group of 1184 children, one had died (sudden unexpected death in infancy), and the parents of $137 \mathrm{did}$ not respond to the questionnaire, which left 1046 children to be studied. Data from maternal and child health centres were available for 1107 children in the screened group and for 1033 controls. Information on the Denver developmental screening test, however, was available for only 859 screened children and 798 controls. We found no obvious differences between
TABLE I-Family and social variables among 1115 children who had been screened by ultrasound in utero and 1046 children who had not as controls. All children aged 8 and 9 year

\begin{tabular}{|c|c|c|c|c|}
\hline & \multicolumn{2}{|c|}{ Screened group } & \multicolumn{2}{|c|}{ Control group } \\
\hline & $\begin{array}{l}\text { No who } \\
\text { responded }\end{array}$ & No $(\%)$ & $\begin{array}{l}\text { No who } \\
\text { responded }\end{array}$ & No $(\%)$ \\
\hline \multicolumn{5}{|l|}{ One or more in the family ${ }^{\star}$ with: } \\
\hline Allergy & 1039 & $528(51)$ & 960 & $458(48)$ \\
\hline Left handedness & 1052 & $356(34)$ & 983 & $350(36)$ \\
\hline Dyslexia & 1109 & $158(14)$ & 1038 & $139(13)$ \\
\hline Years of education (mother): & 1097 & & 1027 & \\
\hline $6-9$ & & $303(28)$ & & $273(27)$ \\
\hline $9-12$ & & $547(50)$ & & $540(52)$ \\
\hline$>12$ & & $247(22)$ & & $214(21)$ \\
\hline Years of education (father): & 1045 & & 982 & \\
\hline $6-9$ & & $246(24)$ & & $241(25)$ \\
\hline $10-12$ & & $431(41)$ & & $395(40)$ \\
\hline$>12$ & & $368(35)$ & & $346(35)$ \\
\hline Family economy: & 1110 & & 1036 & \\
\hline Good & & $664(59)$ & & $580(56)$ \\
\hline Medium & & $418(38)$ & & $424(41)$ \\
\hline Poor & & $28(3)$ & & $32(3)$ \\
\hline $\begin{array}{l}\text { Lived with both parents during } \\
\text { childhood }\end{array}$ & 1112 & $978(88)$ & 1042 & $914(88)$ \\
\hline
\end{tabular}

^Among first and second order relatives.

TABLE II-Number of ultrasound examinations in utero for 1115 children allocated to screening group and 1046 children as controls

\begin{tabular}{lcc}
\hline No of ultrasound scans & $\begin{array}{c}\text { No (\%) in } \\
\text { screened group }\end{array}$ & $\begin{array}{c}\text { No (\%) in } \\
\text { control group }\end{array}$ \\
\hline 0 & $37(3)$ & $846(81)$ \\
1 & $34(3)$ & $130(12)$ \\
$\geqslant 2$ & $1044(94)$ & $70(7)$ \\
$1^{\star}$ & $1026(92)$ & $49(5)$ \\
\hline
\end{tabular}

^At 16-22 weeks' gestation.

screened and control children on any of the collected family or social variables (table I) nor between the children included in the analysis of handedness and those excluded because of missing data.

Complete data on the 10 selected questions from the handedness questionnaire were available for 1663 children $(69 \%)$. In addition, we had information on which hand the child used the most before starting school and family history of left handedness for 466 of the children with missing data. Among the 239 children in the screened group for whom some data were missing, $34(14 \%)$ were reported to be non-right handed before starting school, whereas $37(16 \%)$ of 227 children in the control group for whom some data were missing were non-right handed. Among these children, $91(38 \%)$ in the screened group reported to have one or more left handers among their first and second order relatives compared with $85(37 \%)$ in the control group. In total, $356(34 \%)$ screened children reported having a family history of left handedness compared with 350 $(36 \%)$ control children (table I).

Ultrasonographic exposure in utero of screened and control children is shown in table II. The mean number of scans in the screened group was $2 \cdot 3$ (SD 0.9)

Table III shows the numbers of left handed children and children using either hand equally often in screened and control groups for each item in the questionnaire. With the use of the 10 selected questions we classified $162(19 \%)$ of 861 screened children as non-right handed compared with $120(15 \%)$ of 802 controls (odds ratio $1.32 ; 95 \%$ confidence interval 1.02 to 1.71$)$. Of these, $62(7 \%)$ children in the screened group were classified as left handed compared with 44 $(5 \%)$ control children $(1.34 ; 0.90$ to 2.00$)$. The mean handedness score was 8.70 among screened and 8.95 among control children. The median score was 10 in both groups. The distribution of the handedness score was significantly different between screened and control children $(p=0.02)$

A total of 1654 children could be included in the analyses of impaired neurological development during 


\begin{tabular}{|c|c|c|c|c|c|c|c|c|}
\hline \multirow[b]{2}{*}{ Question } & \multicolumn{3}{|c|}{ Screened group } & \multicolumn{3}{|c|}{ Control group } & \multicolumn{2}{|c|}{ Non-right handedness ${ }^{\star}$} \\
\hline & $\begin{array}{l}\text { No who } \\
\text { responded }\end{array}$ & $\begin{array}{l}\text { No (\%) who } \\
\text { used left } \\
\text { hand }\end{array}$ & $\begin{array}{l}\text { No (\%) who } \\
\text { used either } \\
\text { hand }\end{array}$ & $\begin{array}{l}\text { No who } \\
\text { responded }\end{array}$ & $\begin{array}{l}\text { No }(\%) \text { who } \\
\text { used left } \\
\text { hand }\end{array}$ & $\begin{array}{l}\text { No (\%) who } \\
\text { used either } \\
\text { hand }\end{array}$ & $\begin{array}{l}\text { Odds } \\
\text { ratio }\end{array}$ & $\begin{array}{c}95 \% \\
\text { Confidence } \\
\text { interval }\end{array}$ \\
\hline \multicolumn{9}{|c|}{ Which hand does child use when it: } \\
\hline 1 Draws $†$ & 1095 & $105(10)$ & $4(0)$ & 1022 & $86(8)$ & $4(0)$ & $1 \cdot 14$ & 0.86 to 1.51 \\
\hline 2 Writest & 1094 & $104(10)$ & $2(0)$ & 1022 & $87(9)$ & 0 & $1 \cdot 15$ & 0.86 to 1.54 \\
\hline 3 Deals cards from deck $\dagger$ & 973 & $101(10)$ & $54(6)$ & 905 & $84(9)$ & $24(3)$ & 1.40 & 1.07 to 1.83 \\
\hline 4 Uses bottle openert & 970 & $81(8)$ & $42(4)$ & 909 & $70(8)$ & $18(2)$ & $1 \cdot 35$ & 1.02 to 1.80 \\
\hline 5 Throws ball $t$ & 1054 & $78(7)$ & $103(10)$ & 990 & $66(7)$ & $90(9)$ & $1 \cdot 11$ & 0.87 to 1.41 \\
\hline 6 Uses toothbrush & 1075 & $88(8)$ & $45(4)$ & 1009 & $76(8)$ & $44(4)$ & 1.05 & 0.79 to 1.40 \\
\hline 7 Uses erasert & 1066 & $91(9)$ & $62(6)$ & 1009 & $81(8)$ & $50(5)$ & $1 \cdot 12$ & $0.88 \mathrm{tp} 1.43$ \\
\hline 8 Uses pair of scissorst & 1068 & $84(8)$ & $15(1)$ & 1012 & $65(6)$ & $18(2)$ & $1 \cdot 14$ & 0.85 to 1.54 \\
\hline 9 Threads needle & 771 & $127(16)$ & $38(5)$ & 727 & $111(15)$ & $17(2)$ & $1 \cdot 27$ & 0.99 to 1.64 \\
\hline 10 Sews with needle & 892 & $76(9)$ & $15(2)$ & 843 & $60(7)$ & $12(1)$ & $1 \cdot 22$ & 0.88 to 1.69 \\
\hline 11 Eats with spoon $\dagger$ & 1082 & $95(9)$ & $23(2)$ & 1011 & $76(8)$ & $24(2)$ & $1 \cdot 12$ & 0.84 to 1.50 \\
\hline 12 Presses drawing pin & 901 & $67(7)$ & $120(13)$ & 856 & $62(7)$ & $81(9)$ & 1.31 & 1.03 to 1.67 \\
\hline 13 Spreads butter & 1062 & $94(9)$ & $16(2)$ & 1003 & $79(8)$ & $7(1)$ & 1.23 & 0.92 to 1.65 \\
\hline 14 Twists off lid & 954 & $114(12)$ & $83(9)$ & 903 & $95(11)$ & $69(8)$ & $1 \cdot 17$ & 0.93 to 1.47 \\
\hline 15 Eats with fork $\dagger$ & 1062 & $123(12)$ & $76(7)$ & 997 & 105 (11) & $59(6)$ & $1 \cdot 17$ & 0.93 to 1.47 \\
\hline 16 Takes sweets out of box & 971 & $87(9)$ & $216(22)$ & 914 & $77(8)$ & $165(18)$ & 1.26 & 1.03 to 1.54 \\
\hline 17 Holds ice cream cone & 1021 & $72(7)$ & $241(24)$ & 959 & $62(6)$ & $190(20)$ & 1.24 & 1.02 to 1.51 \\
\hline 18 Cuts with knife $f$ & 1040 & $95(9)$ & $18(2)$ & 989 & $75(8)$ & $21(2)$ & 1.13 & 0.86 to 1.49 \\
\hline 19 Throws dart & 920 & $76(8)$ & $14(2)$ & 875 & $57(7)$ & $15(2)$ & 1.21 & 0.87 to 1.68 \\
\hline 20 Handles clothes peg & 885 & $72(8)$ & $81(9)$ & 818 & $50(6)$ & $60(7)$ & 1.35 & 1.03 to 1.76 \\
\hline 21 Dials telephone number & 1039 & $69(7)$ & $50(5)$ & 970 & $74(8)$ & $48(5)$ & 0.90 & 0.69 to 1.17 \\
\hline
\end{tabular}

*Non-right handedness $=$ use of left hand plus use of either hand.

tQuestions used for analysis.

the first year of life. According to the short version of the Denver developmental screening test $75(9 \%)$ of 859 children in the screened group and $73(9 \%)$ of 798 children in the control group had impaired neurological development $(0.95 ; 0.68$ to 1.33$)$. In all 2128 mothers reported the age when their child started to walk. The mean age for walking was 12 months in both groups.

A total of 2100 children were included in the analyses of deficits in attention, motor control, and perception. Of the 1081 children in the screened group, $147(14 \%)$ were classified as having deficits in attention, motor control, and perception compared to $163(16 \%)$ of 1019 control children $(0 \cdot 83 ; 0.66$ to 1.05$)$.

Allergies, as reported by the mothers, were equally prevalent among the children in the two groups. About a fifth of the children had experienced one or more episodes of allergy which had been treated with prescribed medication.

\section{Discussion}

In this randomised controlled follow up we found a possible association between routine ultrasonography in utero and subsequent non-right handedness among children in primary school. No previous study has examined the relation between ultrasound exposure in utero and handedness of the child. The association with non-right handedness was based on information on 10 out of 21 questionnaire items, on which we had data from 1663 children (69\%). The study question on handedness was one of six initially specified hypotheses, which indicates that the probability of one or more of them being significant $(p<0.05)$ in the predicted

TABLE IV-Different approaches to analysis of association between ultrasonography and non-right handedness in children who had been screened in utero and those who had not

\begin{tabular}{|c|c|c|c|c|c|c|c|}
\hline \multirow[b]{2}{*}{$\begin{array}{l}\text { Selection of items } \\
\text { from handedness } \\
\text { questionnaire }\end{array}$} & \multicolumn{2}{|c|}{ Screened group } & \multicolumn{2}{|c|}{ Control group } & \multirow[b]{2}{*}{$\begin{array}{l}\text { Odds } \\
\text { ratio }\end{array}$} & \multirow[b]{2}{*}{$\begin{array}{l}\text { 95\% Confidence } \\
\text { interval }\end{array}$} & \multirow[b]{2}{*}{$\mathrm{p}$ Value } \\
\hline & No & $\begin{array}{l}\text { No (\%) who } \\
\text { showed non- } \\
\text { right } \\
\text { handedness }\end{array}$ & No & $\begin{array}{l}\text { No (\%) who } \\
\text { showed non- } \\
\text { right } \\
\text { handedness }\end{array}$ & & & \\
\hline 10 Selected items & 861 & $162(19)$ & 802 & $120(15)$ & 1.32 & 1.02 to 1.71 & 0.04 \\
\hline Alternative $1^{\star}$ & 834 & $199(24)$ & 781 & $142(18)$ & 1.41 & 1.11 to 1.79 & 0.005 \\
\hline Alternative $2 \dagger$ & 855 & $138(16)$ & 808 & $110(14)$ & 1.22 & 0.93 to 1.60 & $0 \cdot 15$ \\
\hline Alternative $3 \ddagger$ & 917 & $147(16)$ & 870 & $110(13)$ & 1.32 & 1.01 to 1.72 & 0.04 \\
\hline Alternative $4 \oint$ & 679 & 125 (18) & 654 & $92(14)$ & 1.38 & 1.03 to 1.85 & 0.03 \\
\hline Alternative $5 \|$ & 617 & 105 (17) & 593 & $86(15)$ & $1 \cdot 21$ & 0.89 to 1.65 & 0.2 \\
\hline
\end{tabular}

*10 Items (Nos 1-5, 7, 8, 15, 17, 21), right handedness $\geqslant 9 / 10$.

+10 Items (Nos $1-8,13,18)$, right handedness $\geqslant 9 / 10$.

$\ddagger 12$ Items (Nos $1,2,5-8,11,13,15,17,18,21$ ), right handedness $\geqslant 10 / 12$.

(18 Items (Nos $1-8,11-15,17-21$ ), right handedness $\geqslant 15 / 18$

|| 21 Items, right handedness $\geqslant 17 / 21$. direction by chance is about one in seven $\left(1-0.975^{\circ}=\right.$ $0 \cdot 14)$. Thus, the association $(p=0 \cdot 04)$ between ultrasonography and non-right handedness may be due to chance.

Among the children who were classified as non-right handed we found those who were screened with ultrasound to have an increased prevalence of left handedness. This result was not significant, suggesting that the study had insufficient statistiçal power to resolve the association between ultrasonography and subsequent left handedness in the child.

A strong feature of this study is that a randomised controlled design rules out many of the possible biases that might influence an association between routine ultrasonography and handedness. None the less, the potential for misclassifying children's handedness owing to imprecise measurement may be a threat to the validity of our finding. The 10 questions on which the analysis was based represent various common activities of daily life that received a fairly high response rate. No attempt was made to select items which were likely to distinguish handedness with particularly high sensitivity and specificity. Although our assessment of handedness may be subject to misclassification, it seems unlikely that the bias is differential, depending on ultrasound exposure. We might, however, anticipate a non-differential misclassification, which would ultimately dilute the estimated association (the odds ratio) and give a result which is biased towards the null value of one. ${ }^{18}$

Since the validity of our finding may rest on the classification of handedness we have shown in table IV how the association with ultrasonography may vary depending on which items from the questionnaire have been included in the analysis. Alternative 1 shows that including items such as holding an ice cream cone and dialling a number on the telephone (which is the only item with a question specific odds ratio less than one) instead of items like eating with a spoon or a fork actually strengthens the association with ultrasound (odds ratio $1.41 ; \mathrm{p}=0.005$ ). Conversely, applying another combination of 10 items (alternative 2 ) would weaken the positive association with ultrasound and give a non-significant result. In alternative 3 we used those items to which at least $90 \%$ of each sample responded. This yielded 12 of the 21 items. Alternatives 4 and 5 are combinations using 18 or all 21 items. The problem with the two latter alternatives is the loss of power resulting from incomplete response to the items. Overall, however, the results showed a consistently positive association, suggesting that ultrasound 
screened children had a relative risk of non-right handedness of about $1 \cdot 3$.

We found no association between ultrasonography and impaired neurological development, which agrees with the results of other studies..$^{120}$ Neurological development during the first year of life was assessed from data collected at maternal and child health centres. The precision of the modified version of the Denver developmental screening test has not been formally evaluated, but the study design precludes that assessment of neurological development would be systematically influenced by the children's exposure to ultrasound in utero.

Analogous arguments related to misclassification would apply to the questionnaire, which was designed to measure deficits in attention, motor control, and perception. In this study as many as $15 \%$ of the children were classified as having deficits, but there was no statistical difference between the two groups. The observed prevalence was clearly above the assumed base prevalence of $7 \% .^{14}$ Thus, the instrument may be inaccurate for measuring these deficits. In a study of Swedish preschool children the reported specificity of the questionnaire was $92 \%$, which indicates that the false positive rate may be rather high. ${ }^{15}$

Data in the present study were analysed according to the "intention to treat" principle. Table II shows that $3 \%$ of the children who were offered screening were never exposed to ultrasound in utero whereas $7 \%$ of the controls were exposed several times. During the perceived critical time window at 16 to 22 weeks of pregnancy $5 \%$ of the controls were scanned and $8 \%$ of the screening group were not. Thus, the overlap in ultrasound exposure between the randomised groups was probably of little importance in the interpretation of the results.

In addition, we did exploratory analyses of the association between ultrasound exposure (at 16-22 weeks) and handedness regardless of which screening group the child had been in. By doing so the positive association with non-right handedness was strengthened for 12 of the 21 questions in table III, indifferent for five, and weakened for four questions. The estimated odds ratio of non-right handedness increased from $1 \cdot 32$ to $1 \cdot 34$. After adjusting for family predisposition of left handedness the odds ratio was $1 \cdot 42$.

Many fetuses are exposed to ultrasound from additional sources during pregnancy (fetal heart rate detectors and electronic fetal monitoring). ${ }^{21}$ In this study such use should have been evenly distributed between screened and control children ${ }^{8}$ but may nevertheless represent a background influence, which may weaken the estimated association between ultrasonography and subsequent handedness.

Women who were randomly allocated to routine ultrasonographic screening were typically examined at weeks 19 and 32 of pregnancy. Although a potential biological effect of ultrasound would focus on the developing fetal brain, it does not seem plausible that the low energy levels emitted for diagnostic ultrasound devices (such as the ADR scanners) would cause damage to the fetal brain. Nevertheless, potential harm caused by cavitational effects in the cells cannot be excluded. ${ }^{22}$ Experimental studies in vitro have suggested that ultrasound may influence cell membranes. ${ }^{34}$ Others have hypothesised that ultrasound exposure in utero may influence neuronal migration during a critical stage ${ }^{2}$ which may influence brain development and be an underlying explanation for changes in handedness patterns, dyslexia, or impaired neurological development. We have previously examined the relation between ultrasonography and dyslexia and found no evidence to support the hypothesis. ${ }^{8}$ Thus, the finding of a link between ultrasound

\section{Clinical implications}

- Most women in developed countries have ultrasound examinations during pregnancy

- No problems from the use of ultrasonography have so far been detected

- This study shows a positive association between ultrasound scanning during pregnancy and the proportion of children who are not right handed at the age of 8 and 9 years

- This may be due to chance or it may be the result of ultrasonography's effect on the development of the fetal brain

- This study found no association between ultrasonography during pregnancy and impaired neurological development of the child

and laterality might seem odd, but it is often not recognised just how tenuous the association between dyslexia and lateralisation is. ${ }^{23}$

The present study does not indicate any association between ultrasound in utero and impaired neurological development. We are, however, left with an unexplained positive association between ultrasound screening and non-right handedness. This is one possible chance finding among a number of nonsignificant findings. Theoretically, the concept of pathological left handedness ${ }^{6}$ implies that children with early brain damage to the left hemisphere will have an increased incidence of left handedness. A left hemisphere lesion, however subtle, may cause a shift in hand preference in otherwise genotypic right handers, thus increasing the overall percentage of non-right handedness in these children. ${ }^{6}$ Increased incidence of non-right handedness in a particular population may therefore be a sensitive index of subtle changes in the development of the brain or parts of the brain. We would, however, emphasise the need to replicate the positive association between ultrasound and non-right handedness before it is interpreted as more than a chance finding. Follow up of the children from the Swedish, ${ }^{24}$ Finnish, ${ }^{25}$ or other randomised controlled trials of ultrasonography in pregnancy may help clarify this issue.

The study was supported by the Norwegian Research Council for Science and the Humanities (NAVF), grant no $351.87 / 001$. We also thank the Norwegian Society for Ultrasound Diagnosis in Medicine and Tröndelag medisinske selskap for financial contributions. Ms Nancy Lea Eik-Nes has given valuable comments to the manuscript.

1 Neilson J, Grant A. Ultrasound in pregnancy. In: Chalmers I, Enkin M, Keirse MINC eds. Effective care in pregnancy and childbirh Oxford: Oxford Keirse MJNC, eds. Effect

2 Mole R. Possible hazards of imaging and Doppler ultrasound in obstetrics. Birth 1986;13:29-37

3 Mortimer AJ, Dyson M. The effect of therapeutic ultrasound on calcium uptake in fibroblasts. Ultrasound Med Biol 1988;14:499-506.

4 Liebeskind D, Padawer J, Wolley R, Bases R. Diagnostic ultrasound: timelapse and transmission electron microscopic studies of cells insonated in vitro. Br f Cancer 1982;45:176-86.

5 Geschwind N, Galaburda AM. Cerebral lateralization: biological mechanisms, associations and pathology: part 1. Arch Neurol 1985;42:427-59.

6 Satz P. Pathological left-handedness: an explanatory model. Cortex 1972;8: 121-35.

7 US Department of Health and Human Services. Public Health Service, National Institutes of Health. Diagnostic ultrasound imaging in pregnancy. Washington: NIH, 1984. (Publication No 84-667.)

8 Salvesen $\mathrm{K} \AA$, Bakketeig LS, Eik-Nes SH, Undheim JO, Økland O. Routine ultrasonography in utero and school performance at age 8-9 years. Lancel 1992;339:85-9.

9 Salvesen KA, Vatten LJ, Jacobsen G, Eik-Nes SH, Økland O, Molne K, et al. Routine ultrasonography in utero and subsequent vision and hearing at primary school age. Ultrasound in Obstetrics and Gynecology 1992;2:243-47.

10 Bakketeig LS, Eik-Nes SH, Jacobsen G, Ulstein MK, Brodtkorb CJ, Balstad $\mathrm{P}$, et al. Randomized controlled trial of ultrasonographic screening in pregnancy. Lancet 1984;ii:207-11.

11 Eik-Nes SH, Økland O, Aure JC, Ulstein M. Ultrasound screening in pregnancy: a randomized controlled trial. Lancet 1984;ii: 1347 
12 Rackzowski D, Kalat JW, Nebes R. Reliability and validity of some handedness items. Neuropsychologia 1974;12:43-7.

13 Frankenburg WK, Dodds JB. The Denver developmental screening test. f Pediatr 1967;71:181-91.

14 Gillberg IC. Deficits in attention, motor control and perception: follow-up from preschool to the early teens. Uppsala: Uppsala University, 1987.

15 Rasmussen P, Gillberg C. Perceptual, motor and attentional deficits in sevenyear-old children. Acta Paediatr Scand 1983;72:125-30.

16 SPSS. Statistical package for the social sciences. SPSSX advanced statistics guide. Chicago, Illinois: SPSS, 1985.

17 Kleinbaum DG, Kupper LL, Morgenstern H. Epidemiologic research principles and quantitative methods. New York: Van Nostrand Reinhold, 1982

18 Rothman KJ. Modern epidemiology. Boston: Little Brown, 1986

19 Stark CR, Orleans M, Haverkamp AD, Murphy J. Short- and long term risk after exposure to diagnostic ultrasound in utero. Obstet Gynecol 1984;63 $194-200$
20 Scheidt PC, Stanley F, Bryla DA. One-year follow-up of infants exposed to ultrasound in utero. Am 7 Obstet Gynecol 1978;131:743-8.

21 Salvesen KA, Eik-Nes SH. Bruk av fosterlydsdetektor i allmennpraksis. Tidsskr Nor Laegeforen 1990;110:1506-8.

22 AIUM Bioeffects Committee. Bioeffects considerations for the safety of diagnostic ultrasound. I Ultrasound Med 1988;7:1-38.

23 Bishop DVM. Handedness and developmental disorders. Clinics in Developmental Medicine 110. Oxford: Blackwell Scientific and Philadelphia: JB Lippincot 1990

24 Waldenström U, Axelsson O, Nilsson S, Eklund G, Fall O, Lindeberg S, et al Effects of routine one-stage ultrasound screening in pregnancy: randomised controlled trial. Lancet 1988;ii:585-8.

25 Saari-Kemppainen A, Karjalainen O, Ylöstalo P, Heinonen OP. Ultrasound screening and perinatal mortality: controlled trial of systemic one-stage screening in pregnancy. Lancet 1990;336:387-9

(Accepted 11 May 1993)

\title{
Case-control study of congenital anomalies in children of cancer patients
}

\author{
L Dodds, L D Marrett, D J Tomkins, B Green, G Sherman
}

University of Toronto, Department of Preventive Medicine and Biostatistics, Toronto, Ontario M5S 1 A8 L Dodds, epidemiologist L D Marrett, associate professor

McMaster University, Department of Pediatrics, Hamilton, Ontario L8N $3 Z 5$

D J Tomkins, associate professor

\section{Ontario Cancer}

Treatment and Research

Foundation, Toronto,

Ontario M4H 1 A8

B Green, programme analyst

Health and Welfare

Canada, Laboratory Centre

for Disease Control,

Ottawa, Ontario K1A 0L2

G Sherman, epidemiologist

Correspondence to:

Dr L Dodds, Reproductive

Care Program, Grace

Maternity Hospital, 5980

University Avenue, Halifax,

Nova Scotia, Canada

B3H 4N1.

BMF 1993;307:164-8
Abstract

Objectives-To determine whether the offspring of cancer survivors are at an increased risk of congenital anomalies and whether cancer therapy before conception is associated with such an increase.

Design-Case-control study using computerised record linkage.

Setting-Ontario, Canada.

Subjects-Parents of children born during April 1979 to December 1986 who had a congenital anomaly diagnosed within the first year of life $(45200$ mothers and 41158 fathers) and a matched sample of parents whose children did not have a congenital anomaly (45 200 mothers and 41158 fathers).

Main outcome measures-Cancer diagnosed in either parent before conception and radiotherapy to the pelvis or abdomen or chemotherapy with an alkylating agent.

Results-Among the mothers, 54 cases and 52 controls were identified as having had cancer diagnosed in Ontario (relative risk $=1 \cdot 04,95 \%$ confidence interval 0.7 to 1.5 ) and among the fathers, 61 cases and 65 controls were identified $(0.9,0.7$ to $1 \cdot 4)$. No significant associations were found between congenital anomalies in the offspring and any type of cancer treatment in either the mothers or the fathers.

Conclusions-The risk of congenital anomalies among liveborn offspring whose parents have had cancer or been treated for cancer is not higher than that in the general population.

\section{Introduction}

The survival rate for children and young adults with cancer have improved substantially over the past few decades $^{12}$ largely because of advances in treatment. In the 1970s, chemotherapeutic drugs used in combination were shown to increase complete remission rates. Thus, many children or young adults treated for cancer in the past 10-15 years will have received multiple chemotherapeutic drugs, possibly in addition to radiotherapy. ${ }^{3}$ Because much of the treatment is known to be mutagenic and is designed to interfere with the DNA and normal cellular function, there may be adverse effects on reproduction.

Although some animal studies support the relation between radiation and chemical exposure and abnormalities in the offspring, ${ }^{46}$ evidence in humans is inconclusive. The higher rates of adverse reproductive outcomes, including congenital anomalies, found among mothers treated with radiotherapy before con- ception are thought to be primarily due to radiation induced uterine damage rather than to germ cell mutations. ${ }^{7-9}$ Although most studies have not found an association between cancer therapy and congenital anomalies in the offspring, ${ }^{70-11}$ the power to detect moderate increases in risks has generally been limited and few have looked specifically at conditions that might be expected to result from a therapy induced germ cell mutation.

We conducted a case-control study to determine the association between congenital anomalies in the children of those who had cancer diagnosed or treated before conception. We also examined the risks associated with specific cancer therapies and the risks of specific anomalies that could be produced by a new mutation.

\section{Subjects and methods}

The figure summarises the methods used in the study. Cases were defined as the parents of children who were recorded in the database of the Canadian

\section{Identification of children in Ontario with a congenital anomaly diagnosed before age I, from \\ Canadian congenital anomalies surveillance system

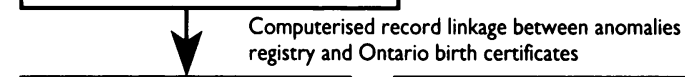

Cases: parents of children with a congenital anomaly identified from child's birth certificate

Controls: parents of children without a congenital anomaly selected from birth certificate file

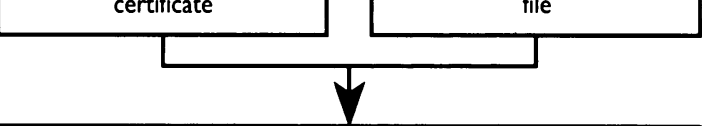

Additional identifying data on parents abstracted from original birth certificates and added to case-control file

Computerised record linkage Cotween case-control file and Ontario cancer registry

Case and control parents with a diagnosis of cancer identified from Ontario cancer registry

Treatment data abstracted from medical records of cases and controls identified in cancer registry

Design of study 